\title{
Representações e percepções na pesquisa em Saúde Coletiva
}

\author{
I Kenneth Rochel de Camargo Jr. |
}

Este número de Physis marca seu vigésimo aniversário. Em 1991, tendo Joel Birman como seu primeiro editor, a nova revista se propunha a "reunir trabalhos de pesquisa oriundos de diferentes áreas de conhecimento [...] dando lugar tanto aos que circulam em campos de objetividade já constituídos, quanto àqueles que promovam a abertura de novos espaços de investigação".

Desde então logramos vários avanços, que colocaram Physis entre as principais revistas do campo em nosso país, entre os quais destacamos sua inclusão no portal SciELO e posterior ampliação de sua periodicidade para trimestral. A demanda de autores pela publicação nas nossas páginas vem crescendo aceleradamente, ultrapassando em muito nossa capacidade de publicação, o que nos leva por vezes a não conseguir a agilidade que gostaríamos na resposta a nossos colaboradores. Em parte isto se deve também à dificuldade em conseguir pareceres em número, qualidade e rapidez adequados, dificuldade compartilhada por praticamente todos os editores de revistas científicas. Em boa parte acreditamos que isto se deva à cobrança por vezes exagerada de publicação de artigos, o que demanda de todos nós maior reflexão.

Uma boa nova neste aniversário foi a obtenção de recursos junto ao CNPq para a publicação dos números deste ano. Além da manutenção da publicação com a qualidade que buscamos, pretendemos o mais rapidamente possível completar a colocação de todos os números passados da revista no portal SciELO.

Como nas edições anteriores, para não comprometer a publicação de artigos já aprovados, o tema deste número foi formado a partir de artigos originalmente submetidos como temas livres. Ao contrário de edições anteriores, o tema 
foi definido a partir de uma dada perspectiva de investigação, cada vez mais adotada em nossa área. Vários estudos têm buscado explorar a subjetividade de diversos sujeitos como chave de compreensão de fenômenos complexos abrangendo vários aspectos da Saúde Coletiva - formação profissional, práticas assistenciais, prevenção - frequentemente objetivando a produção de subsídios para intervenções e formulação de políticas.

Abrindo o tema, Longhi e Canton apresentam as versões contraditórias do conceito de cidadania identificadas através de grupos focais com usuários de uma unidade de saúde de São Paulo, propondo que tais contradições geram obstáculos importantes para a efetiva participação popular na gestão do SUS. Baralhas e Pereira, a seguir, descrevem as representações de agentes comunitários de saúde sobre seu trabalho, elaboradas a partir da análise de entrevistas semiestruturadas, mostrando as dificuldades encontradas pelos mesmos para efetivamente contribuir para a reorientação do modelo assistencial. Willrich et al., por sua vez, apresentam os sentidos presentes nas práticas discursivas dos profissionais acerca da atenção à crise nos Centros de Atenção Psicossocial. Botti e Rego analisam o papel do preceptor na residência médica, com base em um estudo das percepçôes dos preceptores de um hospital de ensino. Cotta et al. analisam as representações sobre a hipertensão arterial de usuárias de uma unidade de APS, portadoras desta condição. Gomes et al. trazem os resultados de estudo de abrangência nacional que analisou os sentidos atribuídos por usuários homens à atenção básica à saúde, visando a subsidiar a construção de indicadores qualitativos de satisfação. Gonze e Silva, fechando o tema, tratam em seu texto de estudo empírico sobre as concepções de integralidade apresentadas por professores de cursos de graduação na área de saúde.

Nos temas livres, Martelli et al. abordam a estratégia de atenção domiciliar à saúde, alternativa à internação de determinados pacientes, por meio da descrição do perfil sociodemográfico e clínico da população assistida pelo programa HU em Casa, do Hospital Universitário Clemente de Faria da Universidade Estadual de Montes Claros. Cuginotti descreve a percepção de usuários de um seguro privado de saúde sobre a perspectiva de implantação de atividades nos moldes da Estratégia de Saúde da Família no âmbito dos serviços que contrataram. Santos e Augusto apresentam um modelo complexo para a descrição dos processos de propagação da dengue, como subsídio para a elaboração de políticas preventivas 
consistentes. Kornis, Maia e Fortuna abordam a Política Nacional de Saúde

Bucal, analisada a partir do seu financiamento. Lima e Trad apresentam estudo etnográfico de uma clínica de dor, tomada como artefato complexo da atenção à saúde. Sabino e Luz partem de um conto de Machado de Assis para discutir aspectos centrais das teorias sociais, no que se refere à construção de identidade e subjetivação. Silva e Nardi tratam da construção de uma rede social, política e jurídica de combate à discriminação por orientação sexual em nosso país. Santos et al. fazem uma análise de publicações que abordam a questão da violência escolar, com referencial baseado na obra de Paulo Freire e Pedro Demo. Santos e Stipp descrevem, a partir da análise de entrevistas, a trajetória de doadores de sangue num serviço da cidade do Rio de Janeiro. Novellino apresenta análise, com base em dados da PNAD, da situação socioeconômica de mães adolescentes. Melo et al. trazem informações sobre o uso de álcool em populações indígenas da Paraíba, elaboradas em estudo exploratório com entrevistas semiestruturadas. 